\title{
PENERAPAN MODEL CONTEXTUAL TEACHING AND LEARNING (CTL) UNTUK MENINGKATKAN HASIL BELAJAR MATEMATIKA TENTANG BANGUN RUANG SISWA KELAS V SDN 1 WALUYOREJO TAHUN AJARAN 2019/2020
}

\author{
Neni Anggriyaningsih', Wahyudi' ${ }^{2}$, Ratna Hidayah ${ }^{3}$ \\ Universitas Sebelas Maret \\ neniningsih65@student.uns.ac.id
}

\section{Article History \\ accepted 01/06/2020}

\begin{abstract}
The research aimed to: (1) describe the steps of Contextual Teaching and Learning (CTL) model in improving mathematics learning outcomes about solid figures, (2) improve mathematics learning outcomes about solid figures by applying Contextual Teaching and Learning (CTL) model, (3) describe obtacle and solution in applying Contextual Teaching and Learning (CTL) model in improving mathematics learning outcomes about solid figures.

It was collaborative classroom action research conducted in three cycles and six meetings. Each cycle consisted of planning, implementation, observation, and reflection. The subjects were teacher and 33 students of fifth grade at SDN 1 Waluyorejo in academic year of 2019/2020. The types of data were qualitative and quantitative. Data collection techniques included observation, interviews, and tests. The data validity used triangulation of techniques and triangulation of sources. Data analysis included data reduction, presentation, and drawing conclusions The results showed that: (1) the steps in applying the Contextual Teaching and Learning (CTL) model were: (a) the students developed their skills, (b) the students carried out discovery activities, (c) the teacher encouraged the students to ask questions, (d) the students worked in group, (e) the students presented concrete objects, (f) the students made reflection, and $(g)$ the teacher made assessment; (2) the application of Contextual Teaching and Learning (CTL) model improved mathematics learning outcomes about solid figures. It was proven by the average of student mastery learning. The averages of cycle 1 were $87,87 \%$ in first meeting and $90,90 \%$ in second meeting. The averages of cycle II were $87,87 \%$ in first meeting and $93,93 \%$ in second meeting. The averages of cycle III were $90,90 \%$ in first meeting and $93,93 \%$ in second meeting; (3) the obstacle was that the teacher was difficult to accurately evaluate the contribution of individual student within group work while the solution was that the teacher needed to focus during process of group work. It concludes that the application of Contextual Teaching and Learning (CTL) model improves mathematics learning outcomes about solid figures to fifth grade students of SDN 1 Waluyorejo in academic year of 2019/2020.
\end{abstract}

Keywords: CTL Model, Learning Outcomes, Mathematics

\begin{abstract}
Abstrak: Penerapan Model Contextual Teaching and Learning (CTL) untuk Meningkatkan Hasil Belajar Matematika tentang Bangun Ruang Siswa Kelas V SDN 1 Waluyorejo Tahun Ajaran 2019/2020. Tujuan penelitian ini: (1) mendeskripsikan langkah-langkah penerapan model Contextual Teaching and Learning (CTL), (2) meningkatkan hasil belajar matematika tentang bangun ruang, dan (3) mendeskripsikan kendala dan solusi penerapan model Contextual Teaching and Learning (CTL). Penelitian tindakan kelas kolaboratif ini dilaksanakan dalam tiga siklus enam pertemuan. Subjek penelitian ini adalah guru dan siswa kelas V SDN 1 Waluyorejo tahun ajaran 2019/2020. Data yang digunakan berupa data kualitatif dan kuantitaif. Teknik pengumpulan data menggunakan observasi, wawancara, dan tes. Validitas data menggunakan triangulasi teknik dan sumber. Analisis data kuantitatif dan kualitatif yang meliputi reduksi data, penyajian data, dan penarikan kesimpulan. Hasil penelitian ini yaitu: (1) penerapan model Contextual Teaching and Learning (CTL) untuk meningkatkan hasil belajar matematika tentang bangun ruang dilaksanakan dengan langkah-langkah: (a) anak mampu mengembangkan kemampuan sendiri, (b) melakukan kegiatan penemuan, (c) mendorong siswa bertanya, (d) belajar kelompok, (e) memunculkan model yaitu menghadirkan benda konkret, $(\mathrm{f})$
\end{abstract}


Volume 8 Nomor 2 Tahun 2020

refleksi, dan (g) penilaian; (2) penerapan model Contextual Teaching and Learning (CTL) dapat meningkatkan hasil belajar matematika tentang bangun ruang pada siswa kelas V SDN 1 Waluyorejo tahun ajaran 2019/2020, hal ini dapat dilihat dari persentase rata-rata ketuntasan siswa pada siklus I pertemuan $1=87,87 \%$, pertemuan $2=90,90 \%$, pada siklus II pertemuan 1 $=87,87 \%$, pertemuan $2=93,93 \%$, dan pada siklus III pertemuan $1=90,90 \%$, pertemuan $2=$ 93,93\%; (3) kendala dalam penelitian ini adalah masih guru belum maksimal dalam menilai proses kerja siswa dalam kelompok, adapun solusi dari kendala tersebut adalah guru lebih memfokuskan dan memperhatikan dengan seksama proses kerja siswa dalam kelompok.

Kata Kunci: Model CTL, Hasil belajar, Matematika 


\section{PENDAHULUAN}

Pada abad 21 ini dibutuhkan sistem pendidikan yang mampu menciptakan sumber daya manusia yang berkualitas. Hal ini dapat dilihat dari manusia yang mampu menguasai keilmuan, memiliki keterampilan metakognitif, mampu berpikir secara kritis, kreatif, dan mampu bekerja sama secara efektif, Greenstein (Sugiyarti, Arif \& Mursalin, 2018: 440). Tujuan pendidikan abad 21 diwujudkan pemerintah melalui kurikulum 2013 yang berbasis pada siswa. Di sekolah formal pada umumnya sudah dituntut untuk menerapkan keterampilan 4C (Critical Thinking, Communiaction, Collaboration, Creativity). Tujuan pendidikan abad 21 dapat diwujudkan melalui pemberian ilmu pengetahuan kepada siswa. Oleh karena itu, seorang guru harus menguasai kompetensi untuk menunjang profesionalitasnya dalam mempersiapkan siswa menghadapi kebutuhan pendidikan abad 21. Selain memberikan ilmu pengetahuan, tugas guru juga harus mampu membentuk karakter serta kepribadian peserta didiknya, dan kemampuan guru dalam memadukan materi, sumber media maupun kurikulum. Pemberian ilmu kepada siswa salah satunya yaitu melalui pembelajaran matematika. Pembelajaran matematika di sekolah dapat menjadii salah satu cara dalam mewujudkan tujuan pendidikan abad 21. Hal ini sejalan dengan pendapat Wardhani (Etrina, Anriani \& Fathurrohman, 2018: 2) yang mengungkapkan bahwa tujuan pembelajaran matematika yaitu membantu siswa memahami konsep dasar matematika, menggunakan penalaran, mampu memecahkan berbagai persoalan, mengungkapkan gagasan, dan mempunyai sikap menghargai manfaat matematika dalam kehidupan.

Berkaitan dengan hal tersebut, salah satu mata pelajaran yang ada di SD yaitu matematika. Matematika menuntut siswa untuk berfikir kritis serta mampu mengungkapkan gagasan. Tujuan pembelajaran matematika yaitu membantu siswa memahami konsep dasar matematika, menggunakan penalaran, mampu memecahkan berbagai persoalan, mengungkapkan gagasan, dan mempunyai sikap menghargai manfaat matematika dalam kehidupan,Wardhani (Etrina, Anriani \& Fathurrohman, 2018: 2). Dalam hal ini guru harus dapat menciptakan suasana pembelajaran yang memungkinkan untuk meningkatkan keaktifan siswa dalam mengikuti proses pembelajaran sehingga tujuan pembelajaran yang telah ditentukan dapat tercapai dan akan terlihat dari hasil belajar peserta didik.

Berdasarkan hasil observasi pembelajaran matematika di kelas $\mathrm{V}$ dan wawancara dengan guru kelas V SDN 1 Waluyorejo pada hari Kamis, 7 November 2019, didapatkan informasi bahwa (1) dalam pembelajaran guru masih menggunakan model pembelajaran konvensional salah satunya yaitu pembelajaran masih berpusat pada guru, (2) kegiatan belajar belum memberikan pengalaman nyata untuk siswa, (3) guru belum menghubungkan materi pelajaran dengan kehidupan sehari-hari, (4) hasil belajar siswa rendah hal ini dibuktikan dengan nilai PTS (Penilaian Tengah Semester) terdapat $87 \%$ atau 29 dari 33 siswa belum mencapai KKM.

Dari uraian di atas, alternatif pemecahan masalah yang dianggap sesuai untuk mengatasi permasalahan tersebut adalah dengan menggunakan model Contextual Teaching and Learning (CTL). Fadillah, dkk (2017: 102) mengemukakan bahwa model Contextual Teaching and Learning (CTL) merupakan suatu proses pembelajaran yang mempermudah guru mengaitkan materi pelajaran dengan kehidupan nyata, serta membantu siswa menghubungkan pengetahuan serta penerapannya dalam kehidupan. Alasan mengapa menggunakan model Contextual Teaching and Learning (CTL) sebagai alternatif pemecahan masalah tersebut karena, model (CTL) merupakan model pembelajaran yang mampu meniciptakan suasana pembelajaran yang bermakna karena siswa diberikan kesempatan untuk menemukan sendiri materi yang akan dipelajari (Nurhidayah, Yani, Nurlina, 2016:166). Dengan menggunakan model Contextual Teaching and Learning (CTL) ini siswa dituntut aktif dalam menemukan sendiri materi yang akan dipelajari dan mampu menerapkan dalam kehidupan sehari- 
hari serta mendapatkan hasil belajar yang baik. Penelitian lainnya yang sesuai dengan penelitian ini adalah penelitian menurut Jamalia (2018: 83), yang mampu meningkatkan hasil belajar matematika melalui penerapan model Contextual Teaching and Learning (CTL).

Berdasarkan latar belakang di atas maka peneliti tertarik untuk melakukan penelitian tindakan kelas yang bertujuan untuk: (1) mendeskripsikan langkah-langkah penerapan model Contextual Teaching and Learning (CTL) dalam peningkatan hasil belajar matematika tentang bangun ruang pada siswa kelas V SDN 1 Waluyorejo tahun ajaran 2019/2020, (2) meningkatkan hasil belajar matematika tentang bangun ruang dengan menerapkan model Contextual Teaching and Learning (CTL) pada siswa kelas V SDN 1 Waluyorejo tahun ajaran 2019/2020, (3) mendeskripsikan kendala dan solusi penerapan model Contextual Teaching and Learning (CTL) dalam peningkatan hasil belajar matematika tentang bangun ruang pada siswa kelas V SDN 1 Waluyorejo tahun ajaran 2019/2020.

\section{METODE}

Penelitian ini merupakan penelitian tindakan kelas yang dilaksanakan secara kolaboratif antara peneliti dengan guru kelas. Guru kelas bertindak sebagai pihak yang melakukan pembelajaran, sedangkan peneliti bertindak sebagai pengamat dan perancang pembelajaran. Subjek penelitian ini adalah seluruh siswa kelas V SDN 1 Waluyorejo tahun ajaran 2019/2020 dengan jumlah 33 siswa yang terdiri dari 15 siswa laki-laki dan 18 siswa perempuan.

Data pada penelitian ini ada dua macam yaitu data mengenai penerapan model Contextual Teaching and Learning (CTL) dan data mengenai hasil belajar matematika tentang bangun ruang. Sumber data dalam penelitian ini yaitu siswa kelas $\mathrm{V}$, guru kelas $\mathrm{V}$, dan dokumen. Adapun teknik pengumpulan data yang digunakan adalah observasi, wawancara, dan tes. Uji validitas data menggunakan triangulasi teknik dan sumber. Teknik analisis data yang digunakan dalam penelitian ini yaitu reduksi data, penyajian data, dan penarikan kesimpulan sesuai model analisis data menurut Miles \& Huberman (Sugiyono, 2016: 247-252).

Aspek yang diukur dalam indikator kinerja penelitian ini adalah pelaksanaan langkah-langkah model Contextual Teaching and Learning (CTL) dan ketuntasan hasil belajar setelah pelaksanaan pembelajaran menggunakan model Contextual Teaching and Learning (CTL) dengan persentase yang ditargetkan sebesar $85 \%$. Adapun prosedur penelitian ini menggunakan model penelitian tindakan kelas menurut (Arikunto, 2013: 137) yang terdiri dari empat tahapan, yaitu (1) perencanaan, (2) pelaksanaan, (3) observasi, dan (4) refleksi.

\section{HASIL DAN PEMBAHASAN}

Penerapan model Contextual Teaching and Learning (CTL) untuk meningkatkan hasil belajar matematika tentang bangun ruang pada siswa kelas $V$ SDN 1 Waluyorejo dilakukan dalam tiga siklus. Satu siklus terdiri dari empat tahapan, yaitu tahap perencanaan, pelaksanaan, observasi, dan refleksi. Setiap siklus terdiri dari dua pertemuan dengan alokasi waktu 70 menit setiap pertemuan.

Proses pembelajaran dilaksanakan dengan langkah-langkah: (1) anak mampu mengembangkan kemampuan sendiri, (2) melakukan kegiatan penemuan, (3) mendorong siswa bertanya, (4) belajar kelompok, (5) memunculkan model yaitu menghadirkan benda konkret, (6) refleksi, (7) penilaian. Langkah-langkah yang digunakan oleh peneliti mengacu pada langkah-langkah yang dikemukakan oleh Hasibuan (2014: 10), Aqib (2015: 6), dan Putra (2013: 257). Hasil observasi penerapan model Contextual Teaching and Learning (CTL) mengalami peningkatan pada setiap siklusnya hingga mencapai indikator kinerja penelitian yang ditargetkan sebesar $85 \%$. 
Volume 8 Nomor 2 Tahun 2020

Tabel 1. Persentase Hasil Observasi Penerapan model Contextual Teaching and Learning (CTL) terhadap Guru dan Siswa

\begin{tabular}{lcccccc}
\hline \multirow{2}{*}{ Keterangan } & \multicolumn{2}{c}{ Siklus I } & \multicolumn{2}{c}{ Siklus II } & \multicolumn{2}{c}{ Siklus III } \\
\cline { 2 - 7 } & Pert 1 & Pert 2 & Pert 1 & Pert 2 & Pert 1 & Pert 2 \\
\hline Tuntas (\%) & 87,87 & 90,90 & 87,87 & 93,93 & 90,90 & 93,93 \\
\hline Belum Tuntas (\%) & 12,12 & 9,09 & 12,12 & 6,06 & 9,09 & 3,03 \\
\hline Rata-rata & 70,82 & 72,73 & 76,27 & 85,61 & 84,94 & 86,76 \\
\hline Nilai Tertinggi & 87 & 93 & 100 & 100 & 100 & 100 \\
\hline Nilai Terendah & 10 & 13 & 20 & 50 & 47 & 50 \\
\hline
\end{tabular}

Berdasarkan tabel 1, diketahui bahwa proses pembelajaran pada siklus I, II, dan III selalu meningkat. Peningkatan hasil pengamatan terhadap guru dari siklus I ke siklus II sebesar 5,69\%, dari siklus II ke siklus III mengalami peningkatan sebesar $3,16 \%$. Peningkatan hasil pengamatan terhadap siswa dari siklus I ke siklus II sebesar $5,98 \%$, dari siklus II ke siklus III mengalami peningkatan sebesar 2,2\%. Pada siklus III, baik guru dan siswa, hasil pengamatan sudah mencapai target yaitu $85 \%$.

Tabel 2. Analisis Hasil Belajar Siswa Siklus I, II, dan III

\begin{tabular}{ccccc}
\hline No & Siklus & \multicolumn{3}{c}{ Tuntas (\%) } \\
\cline { 3 - 5 } & & Pertemuan I & Pertemuan II & Rata-rata \\
\hline 1 & I & 87,87 & 90,90 & 89,38 \\
2 & II & 87,87 & 93,93 & 90,90 \\
3 & III & 90,90 & 93,93 & 92,41 \\
\hline
\end{tabular}

Berdasarkan tabel 2, diketahui bahwa rata-rata ketuntasan hasil belajar siswa setelah guru menerapkan model Contextual Teaching and Learning (CTL) terhadap pembelajaran matematika pada siklus I, II, dan III selalu meningkat. Peningkatan persentase siswa yang tuntas dari siklus I ke siklus II sebesar $1,52 \%$, dari siklus II ke siklus III sebesar $1,51 \%$. Rerata ketuntasan pada siklus III sebesar $92,41 \%$ sudah mencapai target indikator kinerja penelitian yaitu $85 \%$.

Penerapan model Contextual Teaching and Learning (CTL) pada siswa mampu meningkatkan keaktifan siswa dan memperkuat pemahaman konsep belajar yang telah didapatkan. Data di atas membuktikan pendapat Mulyono (Permatasari \& Muslim, 2014: 49) di dalam penelitiannya mengemukakan bahwa model Contextual Teaching and Learning (CTL) dapat meningkatkan keaktifan siswa dan mampu memotivasi untuk belajar serta didukung juga dengan pendapat Surdin (2018: 58) yang menguraikan beberapa kelebihan model Contextual Teaching and Learning (CTL) dalam pembelajaran yaitu: (1) pembelajaran akan lebih bermakna dan nyata, (2) belajar menjadi lebih produktif, dan (3) pembelajaran mampu menumbuhkan penguatan konsep pada siswa.

Alasan mengapa hasil belajar meningkat setelah menerapkan model Contextual Teaching and Learning (CTL) pada pembelajaran matematika yang telah dilakukan ialah; (1) anak mampu mengembangkan kemampuan sendiri, kegiatan ini merupakan kegiatan yang diarahkan pada keaktifan siswa, guru membimbing siswa agar mampu mengungkapkan pengetahuan awal yang dimiliki sehingga guru bukan satu-satunya sumber dalam belajar, hal ini sesuai dengan pendapat Ayuwanti (2016:105-106) yang mengemukakan bahwa ketika guru memberikan kesempatan kepada siswa untuk mengungkapkan pengetahuannya maka siswa akan termotivasi untuk semangat belajar dan mampu menciptakan suasana belajar yang menarik serta akan berpengaruh terhadap hasil belajar, (2) melakukan kegiatan penemuan, kegiatan ini yaitu menciptakan suasana belajar yang lebih bermakna dan nyata serta mampu menambah semangat belajar karena melibatkan siswa secara langsung dalam 
kegiatan penemuan, sesuai dengan hasil penelitian Handini, Gusrayani \& Panjaitan (2016: 453) yang mengemukakan bahwa ketika anak mampu menemukan sendiri materi yang akan dipelajari maka siswa akan lebih mengingat materi tersebut sehingga akan berpengaruh terhadap hasil belajar, (3) mendorong siswa bertanya, kegiatan ini dipandang sebagai kegiatan guru untuk membimbing dan menilai kemampuan berpikir siswa, bagi siswa bertanya merupakan bagian penting dalam proses belajar mengajar karena siswa dapat menggali informasi, mengkonfirmasikan apa yang sudah diketahui, dan mengarahkan perhatian pada aspek yang belum diketahuinya, sesuai dengan pendapat Mustakim \& Solikhin (2015:80) yang memaparkan bahwa bertanya dapat berdampak baik pada hasil belajar karena siswa selalu ingin belajar pada hal-hal yang belum diketahui, (4) belajar kelompok, dalam belajar kelompok siswa diberikan kesempatan untuk bertukar ide dan pendapat dengan teman kelompoknya, setiap kelompok juga berusaha dalam pemecahan persoalan yang disajikan guru melalui Lembar Kerja Siswa (LKS), dengan hal ini dapat meningkatkan keaktifan siswa dan menambah pengetahuan siswa sesuai dengan pendapat Ridwanulloh, Jayadinata \& Sudin (2016: 740) yang mengemukakan bahwa belajar kelompok merupakan salah satu cara belajar dengan teman untuk saling bertukar pendapat dan menyempurnakan hal-hal yang belum diketahui, dengan adanya belajar kelompok maka pengetahuan siswa akan beragam serta mampu berpengaruh terhadap hasil belajar, (5) memunculkan model yaitu menghadirkan benda konkret, ketika guru menghadirkan benda konkret yang berhubungan dengan kehidupan sehari-hari, siswa lebih antusias dalam menanggapi dan materi yang disampaikan memudahkan siswa memahaminya karena ilmu pengetahuan yang didapat tertanam lebih kuat serta dapat mengaplikasikannya dalam kehidupan sehari-hari, seperti yang dikemukakan oleh Setyawan dan Leonard (2017: 741) bahwa menghadirkan konteks atau contoh nyata yang berhubungan dengan materi yang dipelajari akan memperjelas apa yang disampaikan dan mudah diterima oleh siswa karena berkaitan dengan kehidupan sehari-hari serta mampu berpengaruh terhadap hasil belajar, (6) refleksi dilakukan bertujuan untuk mengulas kembali materi yang telah dipelajari, siswa dapat menceritakan kembali materi yang telah dipelajari, dengan ini maka dapat memperkuat pemahaman konsep yang telah dipelajari siswa sehingga dapat mempermudah siswa dalam mengerjakan evaluasi, sesuai dengan pendapat Yenti (2016: 8) bahwa mengungkapkan kembali materi yang telah dipelajari akan mempermudah siswa meninggat dan mempermudah dalam mengerjakan evaluasi agar mendapatkan hasil yang baik, (7) penilaian, kegiatan guru ialah menilai hasil evaluasi siswa yang bertujuan mengetahui hasil belajar siswa dan memberitahukan pada siswa teknik penskoran, dengan kegiatan semacam ini siswa mengetahui bobot nilai dan nilai yang mereka peroleh serta mampu meningkatkan motivasi siswa agar mendapatkan nilai yang lebih baik dan bersaing dengan temannya sesuai dengan pendapat Fua, Lukman, \& Aripin (2017:48) bahwa penilaian mampu meningkatkan semangat bersaing antar siswa sehingga siswa berlomba-lomba untuk mendapatkan hasil yang baik.

Dari keseluruhan yang telah dibahas, penerapan model Contextual Teaching and Learning (CTL) efektif untuk meningkatkan hasil belajar siswa. Dalam penelitian ini hasil belajar akan difokuskan pada ranah kognitif atau pengetahuan. Oleh karena itu, hasil belajar pada aspek kognitif yang diukur dalam penelitian ini dapat meningkat. Hasil penelitian di atas memperkuat penelitian sebelumnya yang dilakukan Lexair (2017: 5). Permasalahan yang ada dalam penelitian tersebut yaitu sebagian siswa masih kesulitan memahami materi yang dijelaskan guru, guru menganggap bahwa hanya dirinya yang menjadi sumber belajar, strategi pembelajaran yang guru lakukan kurang bervariasi, masih bersifat demonstrasi, tanya jawab atau penugasan, kemudian peniliti menggunakan model Contextual Teaching and Learning (CTL) untuk meningkatkan hasil belajar matematika, hasil yang didapat adalah penerapan model Contextual Teaching and Learning (CTL) dapat meningkatkan hasil belajar matematika 
tentang bangun ruang. Dengan demikian penerapan model Contextual Teaching and Learning (CTL) dapat meningkatkan hasil belajar matematika tentang bangun ruang yang dilihat dari persentase siswa yang memenuhi ketercapaian target dari siklus I-III.

Kendala penerapan model Contextual Teaching and Learning (CTL) untuk meningkatkan hasil belajar matematika tentang bangun ruang pada siswa kelas V SDN 1 Waluyorejo tahun ajaran 2019/2020 yaitu: (1) guru sulit menggali pengetahuan awal siswa, (2) guru sulit mengajak siswa mengungkapkan hal-hal yang berkaitan dengan bangun ruang, (3) sedikit siswa yang berani bertanya, (4) pembelajaran kelompok didominasi siswa aktif, (5) siswa belum menggunakan media dengan baik untuk presentasi, (6) siswa kurang menghargai kelompok lain ketika presentasi, (7) guru belum sepenuhnya membimbing bekerja kelompok, (8) siswa belum memperhatikan benda yang ditunjukan guru dalam kelompok, (9) siswa belum merangkum secara keseluruhan, (10) guru belum merata dalam menunjuk siswa membacakan rangkuman, (11) guru mendominasi penyamaan persepsi, (12) guru belum maksimal menilai proses kerja kelompok, (13) siswa belum merespons untuk bertanya pada guru, (14) siswa belum termotivasi mempresentasikan hasil diskusi. Solusi permasalahan pada siklus I sampai III yaitu: (1) guru berusaha bertanya hal-hal yang diketahui siswa, (2) guru memberikan pernyataan pancingan agar termotivasi berpendapat, (3) guru memotivasi dan memberikan pertanyaan pancingan, (4) guru mengarahkan untuk membagi pekerjaan, (5) guru membimbing menggunakan media dalam presentasi, (6) guru memfokuskan pada kelompok yang sedang presentasi, (7) guru tidak fokus pada salah satu kelompok, (8) guru memberikan peringatan dan memfokuskan siswa pada penjelasan guru, (9) guru membimbing siswa menulis rangkuman secara lengkap, (10) guru secara acak menunjuk siswa, (11) guru memberikan kesempatan siswa mengungkapkan materi, (12) guru memperhatikan seksama proses kerja dalam kelompok, (13) guru memberikan pertanyaan pancingan, (14) guru memberikan tepuk semangat.

\section{SIMPULAN}

Berdasarkan hasil penelitian dan pembahasan di atas, maka dapat disimpulkan,

1. Penerapan model Contextual Teaching and Learning (CTL) dalam peningkatan hasil belajar matematika tentang bangun ruang pada siswa kelas V SDN 1 Waluyorejo tahun ajaran 2019/2020 dilaksanakan dengan langkah-langkah: (1) anak mampu mengembangkan kemampuan sendiri, (2) melakukan kegiatan penemuan, (3) mendorong siswa bertanya, (4) belajar kelompok, (5) memunculkan model yaitu menghadirkan benda konkret, (6) refleksi, (7) penilaian.

2. Penerapan model Contextual Teaching and Learning (CTL) dapat meningkatkan hasil belajar matematika tentang bangun ruang pada siswa kelas $\mathrm{V}$ SDN 1 Waluyorejo tahun ajaran 2019/2020. Hal ini dapat dilihat dari persentase rata-rata ketuntasan siswa pada siklus I pertemuan $1=87,87 \%$, pertemuan $2=90,90 \%$, pada siklus II pertemuan $1=87,87 \%$, pertemuan $2=93,93 \%$, dan pada siklus III pertemuan $1=90,90 \%$, pertemuan $2=93,93 \%$.

3. Kendala pelaksanaan penerapan model Contextual Teaching and Learning (CTL) dalam peningkatan hasil belajar matematika tentang bangun ruang pada siswa kelas V SDN 1 Waluyorejo tahun ajaran 2019/2020 yaitu: (1) guru sulit menggali pengetahuan awal siswa, (2) guru sulit mengajak siswa mengungkapkan hal-hal yang berkaitan dengan bangun ruang, (3) sedikit siswa yang bertanya, (4) pembelajaran kelompok didominasi siswa aktif, (5) siswa belum menggunakan media dengan baik untuk presentasi, (6) siswa kurang menghargai kelompok lain ketika presentasi, (7) guru belum sepenuhnya membimbing kelompok, (8) siswa belum memperhatikan benda yang ditunjukan guru dalam kelompok, (9) siswa belum merangkum secara keseluruhan, (10) guru belum merata dalam menunjuk siswa membacakan rangkuman, (11) guru mendominasi penyamaan persepsi, 
(12) guru belum maksimal menilai proses kerja kelompok, (13) siswa belum merespons untuk bertanya pada guru, (14) siswa belum termotivasi mempresentasikan hasil diskusi. Solusi permasalahan pada siklus I sampai III yaitu: (1) guru berusaha bertanya hal-hal yang diketahui siswa, (2) guru memberikan pernyataan pancingan agar termotivasi berpendapat, (3) guru memotivasi dan memberikan pertanyaan pancingan, (4) guru mengarahkan untuk membagi pekerjaan, (5) guru membimbing menggunakan media dalam presentasi, (6) guru memfokuskan pada kelompok yang sedang presentasi, (7) guru tidak fokus pada salah satu kelompok, (8) guru memberikan peringatan dan memfokuskan siswa pada penjelasan guru, (9) guru membimbing siswa menulis rangkuman secara lengkap, (10) guru secara acak menunjuk siswa, (11) guru memberikan kesempatan siswa mengungkapkan materi, (12) guru memperhatikan seksama proses kerja dalam kelompok, (13) guru memberikan pertanyaan pancingan, (14) guru memberikan tepuk semangat.

Berkaitan dengan hasil penelitian yang telah dicapai, peneliti mengajukan rekomendasi sebagai berikut: (1) siswa sebaiknya lebih fokus dalam kegiatan pembelajaran, berperan aktif dalam langkah model Contextual Teaching and Learning $(C T L)$, berani bertanya jika ada materi yang belum dipahami, dan percaya diri dalam menyampaikan pendapatnya, (2) guru sebaiknya lebih berusaha dalam mengarahkan siswa untuk fokus dan aktif dalam langkah model Contextual Teaching and Learning (CTL) agar siswa dapat menikmati suasana belajar dan lebih memahami materi yang disampaikan sehingga hasil belajar siswa lebih maksimal, hendaknya membimbing siswa agar lebih percaya diri dan berani bertanya, menjawab dan berpendapat pada saat kegiatan diskusi berlangsung, (3) sekolah sebaiknya menyediakan fasilitas, sarana, dan prasarana serta mendukung guru untuk berinovasi dalam menggunakan model dan media pembelajaran untuk meningkatkan kualitas pembelajaran sebaiknya sekolah menyediakan fasilitas, sarana, dan prasarana serta mendukung guru untuk berinovasi dalam menggunakan pendekatan atau model dan media pembelajaran untuk meningkatkan kualitas pembelajaran, (4) pembaca/peneliti lain hasil penelitian ini sebaiknya dapat dijadikan referensi untuk lebih mempersiapkan dalam menguasai materi sebelum melakukan penelitian.

\section{DAFTAR PUSTAKA}

Aqib, Z. (2015). Model-Model, Media, dan Strategi Pembelajaran Kontekstual (Inovatif). Bandung: Yrama Widya

Ayuwanti, I. (2016). Meningkatkan Aktivitas dan Hasil Belajar Matematika Menggunakan Model Pembelajaran Kooperatif Tipe Group Investigation di SMK Tuma'ninah Yasin Metro. Jurnal SAP, 1 (2), 105-114.

Etrina, Anriani, N., \& Fathurrohman, M. (2018). Pengembangan Bahan Ajar Matematika Berbasis Kompetensi Abad 21 untuk Guru SMP/MTs. Prosiding Seminar dan Diskusi Nasional Pendidikan Dasar, hlm. 1-5. Serang: Magister Pendidikan Matematika Pascasarjana Universitas Sultan Ageng.

Fadillah, A, dkk. (2017). The Effect Of Application Of Contextual Teaching And Learning (CTL) Model-Based On Lesson Study With Mind Mapping Media To Assess Student Learning Outcomes On Chemistry On Colloid Systems. International Journal of Science and Applied Science: Conference Series, 1 (2), 101-108.

Fua1, L,J,. Lukman, A, A,. \& Aripin. (2017). Meningkatkan Hasil Belajar Ipa Melalui Model Pembelajaran Contextual Teaching Learning Pada Siswa Kelas IV SD Negeri Tabanggele, Kecamatan Anggalomoare, Kabupaten Konawe. Jurnal Al-Ta'dib, 10 (2), 37-54. 
Hasibuan, I. (2014). Model Pembelajaran CTL (Contextual Teaching and Learning). Jurnal Logaritma, 2 (1), 1-12.

Jamalia. (2018). Model CTL untuk Meningkatkan Hasil Belajar Matematika Kelas V SDN 104/IX Kedemangan. Jurnal IImiah Kependidikan. 9 (1), 82-89.

Lexair, M, A. (2017). Upaya Meningkatkan Hasil Belajar Bangun Ruang Melalui Model Pembelajaran Contextual Teaching and Learning (CTL) Siswa Kelas V SD Negeri 3 Jarakan Sewon Bantul Yogyakarta. Skripsi Tidak Dipublikasikan, Universitas Negeri Yogyakarta, Yogyakarta.

Mustakim \& Solikhin. (2015). Upaya Meningkatkan Keberanian Siswa Bertanya dan Prestasi Belajar dengan Pembelajaran Think Pair Share (TPS) Berbantuan Media. Jurnal Pendidikan, 16 (2), 74-99.

Nurhidayah , Yani, A., \& Nurlina. (2016). Penerapan Model Contextual Teaching Learning (CTL) terhadap Hasil Belajar Fisika pada Siswa Kelas XI SMA Handayani Sungguminasa Kabupaten Gowa. Jurnal Pendidikan Fisika, 4 (4), 161-174.

Permatasari, S. W. E. \& Muslim, S. (2014). Implementasi Model Pembelajaran Contextual Teaching and Learning (CTL) pada Standar Kompetensi Dasar Memasang Instalasi Penerangan Listrik Di SMKN 7 Surabaya. Jurnal Pendidikan Teknik elektro, 3 (2), 47-53.

Putra, S. R. (2013). Desain Belajar Mengajar Kreatif Berbasis Sains. Yogjakarta: DIVA Press

Ridwanulloh, A, Jayadinata, A.K, \& Sudin, A. (2016). Pengaruh Model Pembelajaran Contextual Teaching and Learning (CTL) terhadap Hasil Belajar Siswa Kelas $\checkmark$ pada Materi Pesawat Sederhana. Jurnal Pena IImiah, 1 (1), 731-740.

Setyawan, A., \& Leonard. (2017). Pengaruh Model Pembelajaran Contextual Teaching and Learning (CTL) terhadap Hasil Belajar Matematika Siswa. Prosiding Diskusi Panel Nasional Pendidikan Matematika, hlm. 736-745. Jakarta: Universitas Indraprasta PGRI Jakarta.

Sugiyarti, L., Arif, A., \& Mursalin. (2018). Pembelajaran Abad 21 di SD. Prosiding Seminar dan Diskusi Nasional Pendidikan Dasar, hlm. 439-444. Jakarta: Universitas Negeri Jakarta.

Sugiyono. (2016). Metode Penelitian Kuantitatif, Kualitatif, dan R\&D. Bandung: Alfabeta Bandung

Surdin. (2018). The Effect of Contextual Teaching and Learning (CTL) Models on learning outcomes of Social Sciences of the material of forms the face of the earth on Class VII of Junior High School. International Journal of Education and Research, 6 (3), 57-64.

Yenti, F. (2016). Penerapan Model Pembelajaran Contextual Teaching and Learning (CTL) terhadap Pemahaman Konsep Matematika Siswa. Jurnal Curricula, 1 (3), 1-10. 